Review Article

\title{
New Insights into the Mechanisms of Chinese Herbal Products on Diabetes: A Focus on the "Bacteria-Mucosal Immunity-Inflammation-Diabetes" Axis
}

\author{
Zezheng Gao, ${ }^{1}$ Qingwei Li, ${ }^{1}$ Xuemin Wu, ${ }^{2}$ Xuemin Zhao, ${ }^{1}$ Linhua Zhao, ${ }^{3}$ and Xiaolin Tong ${ }^{1,2}$ \\ ${ }^{1}$ Department of Endocrinology, Guang'anmen Hospital, China Academy of Chinese Medical Sciences, Beijing 100054, China \\ ${ }^{2}$ Shenzhen Hospital, Guangzhou University of Chinese Medicine, Guangzhou 518034, China \\ ${ }^{3}$ Laboratory of Molecular Biology, Guang'anmen Hospital, China Academy of Chinese Medical Sciences, Beijing 100053, China
}

Correspondence should be addressed to Linhua Zhao; melonzhao@163.com and Xiaolin Tong; tongxiaolin@vip.163.com

Received 4 May 2017; Revised 27 June 2017; Accepted 25 July 2017; Published 15 October 2017

Academic Editor: Cheng Xiao

Copyright (c) 2017 Zezheng Gao et al. This is an open access article distributed under the Creative Commons Attribution License, which permits unrestricted use, distribution, and reproduction in any medium, provided the original work is properly cited.

\begin{abstract}
Diabetes, especially type 2, has been rapidly increasing all over the world. Although many drugs have been developed and used to treat diabetes, side effects and long-term efficacy are of great challenge. Therefore, natural health product and dietary supplements have been of increasing interest alternatively. In this regard, Chinese herbs and herbal products have been considered a rich resource of product development. Although increasing evidence has been produced from various scientific studies, the mechanisms of action are lacking. Here, we have proposed that many herbal monomers and formulae improve glucose homeostasis and diabetes through the BMID axis; B represents gut microbiota, $\mathrm{M}$ means mucosal immunity, I represents inflammation, and $\mathrm{D}$ represents diabetes. Chinese herbs have been traditionally used to treat diabetes, with minimal side and toxic effects. Here, we reviewed monomers such as berberine, ginsenoside, M. charantia extract, and curcumin and herbal formulae such as Gegen Qinlian Decoction, Danggui Liuhuang Decoction, and Huanglian Wendan Decoction. This review was intended to provide new perspectives and strategies for future diabetes research and product.
\end{abstract}

\section{Introduction}

In July 2015, the International Diabetes Federation (IDF) released the seventh edition of "IDF diabetes map," which showed that China had approximately 1.096 million diabetes cases in 2015, ranking the highest in the world. According to the current development trend, the number of diabetes cases in China is projected to reach 150.7 million in 2040. The incidence of diabetes is estimated to increase by $69 \%$ in developing countries and 20\% in developed countries from 2010 to 2030. Thus, schemes in preventing and treating diabetes are warranted. Currently, Chinese herbs for the prevention and treatment of diabetes and its minimal complications are considered advantageous, and a large number of evidencebased clinical studies have confirmed these effects [1-7].

Modern medical technology provides a new way and direction for the prevention and treatment of diabetes. Chinese herbs have been historically and traditionally used in the treatment of diabetes, which dates back to the Qin dynasty (221 to $207 \mathrm{BC}$ ). Globalization and progress in medical science rejuvenate the ancient Chinese herbs, and an increasing number of studies have shown that various specific monomers and Chinese formulae can be used in the prevention and treatment of diabetes through the "Bacteria-Mucosal Immunity-Inflammation-Diabetes" axis (BMID axis). We retrieved the literature and screened out more than 40 relevant Chinese herbs and its derivatives that have been used to treat diabetes regulating multiple targets. We have chosen some of them which have been widely studied and characterized, including monomers and prescriptions. The specific monomers include berberine, $M$. charantia extract, ginsenoside, and curcumin, and prescriptions include Gegen Qinlian Decoction (GGQLD), Danggui Liuhuang Decoction (DGLHD), and Huanglian Wendan Decoction (HLWDD). Here, we attempt to explore the possible mechanisms of action of these in diabetic treatment from 
the perspective of immunology and provide potentially novel therapeutic strategies that may improve clinical treatment on diabetes.

\section{New Insights into Diabetes: "Bacteria- Mucosal Immunity-Inflammation-Diabetes" Axis}

The gut microbiota represents a microbial community located in the intestine, composed of over a trillion microorganisms with hundreds of species, which play an important role in digestion and intestinal mucosal immunity. There is increasing evidence that confirms that the changes in gut microbiota are associated with insulin resistance and diabetes.

\subsection{Diabetes Is Associated with Imbalance of Gut Microbiota.} In mice and humans, there are two main bacterial phyla, Bacteroidetes and Firmicutes, which are found in the gut through metagenomic analysis [8]. The normal mice keep a relative balance among these two bacterial phyla, but the bacterial phylum Firmicutes is increased in obese mice observably [9]. A study has shown that a high-fat diet (HFD) can reduce the number of Bifidobacterium species (spp.), resulting in the development of endotoxemia and diabetes; an oligosaccharide-rich diet increases the number of Bifidobacterium species (spp.) and subsequently reduces the level of inflammation and improves glucose intolerance [10]. The metagenomic analysis revealed that patients with type 2 diabetes had moderate levels of gut microbiota dysbiosis, characterized by the decrease in the abundance of some universal butyrate-producing bacteria and the increase in the abundance of some bacteria which reduce sulfate and antioxidant stress [11]. A human study showed that the number of Faecalibacterium prausnitzii, which was associated with the production of short-chain fatty acids and butyrate, is increased [12]. Gut microbiota of diabetic patients and mice changed significantly, indicating that reversing this change may reduce the incidence of insulin resistance and diabetes.

2.2. Disorder of Mucosal Immunity Leads to Diabetes. Gut microbiota affects insulin resistance and type 2 diabetes mellitus (T2DM) by altering the intestinal epithelial barrier and intestinal mucosal immunity. The main function of the intestinal epithelial barrier is to limit intestinal contents such as water, chyme, and gut microbiota and also to regulate immune responses. The epithelial barrier needs a continuous epithelial cell layer, and the tight junctions are the major characteristic. The tight junctions consist of a complex network of transmembrane proteins, cytoplasmic proteins, and regulatory proteins. There are two pathways: "pore" and "leak". The "pore" pathway is a high-capacity, sizeselective, and charge-selective route, and the "leak" pathway refers to a low-capacity pathway that has limited selectivity [13]. In HFD-induced mice, intestinal bacteria or bacterial products cause the elevation of tumor necrosis factor (TNF) and interleukin- (IL-) 13. These inflammatory factors increase transcription and activity of the myosin light-chain kinase (MLCK) and IL-13-dependent claudin-2 and subsequently increase permeability of "pore" and "leak" pathways and the pass of lipopolysaccharide (LPS) [14-16]. This change leads to an increase in chronic inflammation in the liver, fat, and other tissues and other metabolic diseases. In addition to the intestinal bacterial products, the gut microbiota can also directly pass the intestinal barrier and translocate to the pancreatic lymph nodes, activate NOD-like receptors 2 (NOD2), and contribute to diabetes [17].

The intestinal mucosal immunity is the most important line of defense against intestinal infection through the functions of goblet cells, intestinal epithelial cells (IEC), innate lymphoid cells (ILC), and other rapid responsive immune cells, such as macrophages and neutrophils. The goblet cells and IEC can produce antimicrobial peptides (AMPs) and mucin to prevent pathogens from penetrating the intestine [18]. IEC can secrete anti-inflammatory mediators such as IL-25, IL-33, and transforming growth factor- $\beta$ (TGF- $\beta$ ). These mediators can influence micro-associated molecular patterns (MAMPs) by binding to Toll-like receptors 5 (TLR5) and NOD2. ILC inhibits the body's chronic lowlevel inflammation through the secretion of IL-22, IL-17A, IL-17F, and so forth [19]. HFD can reduce the diversity and alter the distribution balance of gut microbiota and thus reduce the production of mucin and other antimicrobial factors. Invasive bacteria and the associated products alter the intestinal mucosal immunity, and that contributes to the development of T2DM [20].

\subsection{Inflammation Affects Diabetes through Multiple} Pathways. The alternation of intestinal mucosal immunity and increased production of inflammatory factors have been considered to be linked to the development of T2DM. The pathophysiological processes are proposed to mainly include three pathways: (1) The nuclear factor kappa-B (NF- $\kappa \mathrm{B})$ pathway are activated by the inhibitor of nuclear factor kappa-B kinase (IKK) and proinflammatory cytokines such as TNF- $\alpha$, IL-1, and IL-6. The activated IKK and proinflammatory cytokines phosphorylate the inhibitor of $\mathrm{NF}-\kappa \mathrm{B}$ $(\mathrm{I} \kappa \mathrm{B})$. When $\mathrm{I} \kappa \mathrm{B}$ is phosphorylated, $\mathrm{I} \kappa \mathrm{B}$ and $\mathrm{NF}-\kappa \mathrm{B}$ are dissociated, resulting in NF- $\kappa \mathrm{B}$ degradation. Then, NF- $\kappa \mathrm{B}$ enters the nucleus, thereby mediating the expression of a variety of inflammatory genes [21, 22]. (2) IKK regulates insulin receptor substrate serine/threonine phosphorylation, interfering with normal tyrosine phosphorylation and weakening the insulin signal transduction. IKK is currently considered the link between inflammation and insulin resistance (IR). TNF- $\alpha$ and free fatty acid (FFA) activate Jun $\mathrm{N}$-terminal kinase (JNK) and product insulin receptor substrate number 307 serine, which interferes with the insulin signal transduction via the IR/IRS/PI3K pathway. (3) The SOCS family of the cytokine signaling factor (SOCS) pathway mediates cytokine-induced IR. SOCS-1, SOCS-3, and SOCS-6 are involved, which predominantly inhibit the phosphorylation of IRS1 and IRS2 tyrosine residues and accelerate the degradation of IRS1 and IRS2 [23, 24].

2.4. "Bacteria-Mucosal Immunity-Inflammation-Diabetes" Axis. It has been shown that gut microbiota affects the 


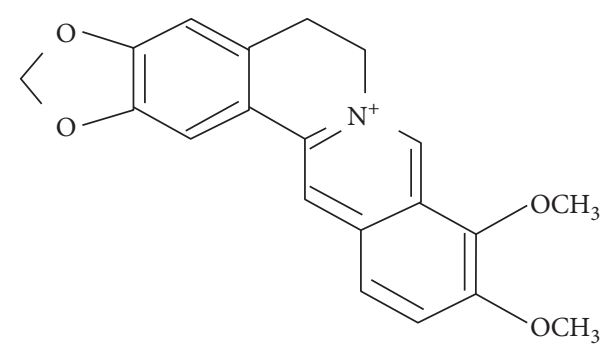

Figure 1: Molecular structure of berberine.

intestinal epithelial barrier and intestinal mucosal immunity, alters the level of inflammation, and influences insulin resistance and diabetes. This potential pathogenesis of diabetes is referred to as the "BMID" axis, "B" represents gut microbiota, "M" represents mucosal immunity, "I" represents inflammation, and of course, " $D$ " represents diabetes. This axis is like a "line" to string most antidiabetic agents together and may provide new perspectives and strategies for future research on diabetes and the development of hypoglycemic drugs.

\section{Herbal Monomers}

Herbal monomers are major effective constituents of Chinese herbs. Studies on monomers are increasing in recent years, because they have specific molecular structure and are easier to be used in mechanism research and observing effective targets of Chinese herbs. Here, we screened out five representative monomers to find out their different functions based on the BMID axis. They have been widely researched and applied in treating diabetes for a long time.

3.1. Berberine. Rhizoma coptidis has been used for centuries in traditional Chinese medicine (TCM) as an antipyretic and alexipharmacons, and its main active component is berberine (BBR, Figure 1) [25]. BBR is an isoquinoline and found in many plants of the berberidaceae family. Recent studies have shown that BBR and its derivatives possess a variety of disease-fighting activities, they regulate the immune system, inhibit inflammation, and reduce insulin resistance $[26,27]$, and they have an anticancer effect likewise; it was reported that BBR inhibits the progression of pancreatic, colon, and breast cancer [28-31].

3.1.1. Effect of BBR on Diabetes. Insulin resistance (IR) is a metabolic state in which insulin inefficiently regulates the tissue and cell for their uptake and utilization of glucose. Nodlike receptor family pyrin domain containing 3 (NLRP3) contributes to obesity-induced inflammation and insulin resistance [32]. A recent study showed that BBR inhibited saturated fatty acid palmitate- (PA-) induced activation of NLRP3 and release of interleukin-1 $\beta$ (IL-1 $\beta$ ) in macrophages by activating AMPK-dependent autophagy, thus reducing inflammation and insulin resistance [26]. An animal study showed that BBR reduced blood TNF- $\alpha$, IL- 6 , and MCP-1 levels of JNK and IKK $\beta$ phosphorylation in obese mice fed with a high-fat diet, as well as indicated that BBR improves insulin resistance possibly through inhibiting the activation of macrophages in adipose tissue [33].

3.1.2. Effect of BBR on Gut Microbiota and Intestinal Mucosal Immunity. Intestinal barrier integrity and immune tolerance are associated with the pathogenesis of diabetes. Defects in the integrity of the mucosal barriers and leakage of the gut microbiome can contribute to the low-grade inflammation of tissues, which is well known to be associated with glucose metabolism in the muscle, liver, and adipose tissue and causes glucose intolerance and T2DM [17, 34]. Recent studies have shown that BBR imparts beneficial effects on the immune cells of the intestinal immune system and influences the expression of intestinal immune factors. It also inhibits the expression of IL- $1 \beta$, IL- 4 , IL-10, MIF, and TNF- $\alpha$ mRNA and reduces the low-grade inflammation [35].

Intestinal microflora is an important factor in mediating the development of obesity-related metabolic disorders (including type 2 diabetes). The current results suggest that $\mathrm{BBR}$ can regulate the intestinal microflora, restore the intestinal barrier, reduce metabolic endotoxemia and systemic inflammation, and improve gut peptide levels in high-fat diet-fed rats; it indicates that BBR is possibly an effective agent for the treatment of obesity and diabetes [36]. A study showed that BBR improved metabolic disorders induced by high-fat diets by modulating the gut-intestinal-brain axis, including changes in the distribution and diversity of microbes, elevation of serum glucagon-like peptide- 1 and neuropeptide $\mathrm{Y}$, decrease in orexin $\mathrm{A}$, and upregulation of glucagon-like peptide-1 receptor mRNA [37].

\subsubsection{BBR Reduces Inflammatory Response in Diabetes} Mellitus. The anti-inflammatory activity of BBR has been observed in in vitro and in vivo studies. In immunocytes (macrophages) [26, 38], cultured metabolic cells (adipocytes and hepatocytes) $[39,40]$, or pancreatic $\beta$ cells $[41]$, BBR treatment reduces the production of TNF- $\alpha$, IL- 6 , IL- $1 \beta$, inducible nitric oxide synthase (iNOS), cyclooxygenase-2 (COX-2), matrix metalloprotease 9 (MMP9), monocyte chemoattractant protein-1 (MCP-1), and CRP and haptoglobin (HP) increases the transcription of Nrf2-targeted antioxidative genes $[N A D P H$ quinone oxidoreductase-1 (NQO-1), heme oxygenase-1 (HO-1)] [37-41]. The insulin-sensitizing effect of HepG2 cells is closely related to its antiinflammatory activity. BBR administration significantly decreased serine phosphorylation and increased tyrosine phosphorylation of IRS in HepG2 cells, which improved insulin signaling and thus in turn ameliorated insulin resistance [40]. BBR inhibited inflammation, ameliorated insulin resistance, and reduced the production of proinflammatory cytokines such as IL-6, IL-17, TNF- $\alpha$, and interferon- $\gamma$ $(\mathrm{IFN} \gamma)$ in NOD mice $[42,43]$. Furthermore, BBR increased the ratios of anti-inflammatory/proinflammatory cytokines, such as IL-10/IL-6, IL-10/IL-1 $\beta$, and IL-10/TNF- $\alpha$ [43].

3.2. M. charantia. M. charantia, also known as bitter melon, has been used for centuries in TCM as an antipyretic and alexipharmacon herb. Recent studies have shown that $M$. charantia can ameliorate oxidative stress, hyperlipidemia 
[44], inflammation [45], and apoptosis [46]. It also regulates glucose metabolism by acting as a "plant insulin" [47] and presents antidiabetic and antioxidant activities [48].

3.2.1. Effect of M. charantia on Diabetes. Momordica charantia ( $M$. charantia) is a widely used traditional remedy for diabetes. It has been proven to be beneficial to insulin resistance, prediabetes, weight losing, and glycemic control in cultured cells, animal models, and human studies [49]. M. charantia can repair damaged beta cells, increase insulin levels, and also enhance insulin sensitivity. It inhibits the intestinal glucose absorption by inhibiting glucosidase and enterotoxin activities. It also stimulates the synthesis and release of thyroid hormones and adiponectin and enhances the activity of AMP-activated protein kinase (AMPK) [50]. A recent study showed that compared with metformin, the application of $M$. charantia in diabetes patients had lower probability of hypoglycemia although it is less effective than metformin in lowering blood glucose [51]. In addition, M. charantia has a superposition effect when taken with other hypoglycemic agents at the same time, and thus, patients may achieve better management of blood glucose [52]. M. charantia also reduces the obesity of rats fed with a high-fat diet $[53,54]$.

3.2.2. M. charantia Changes Gut Microbiota. The effect of $M$. charantia on intestinal flora and inflammation has been reported in obese rats fed with high-fat diets. A result showed that although the exact effect of $M$. charantia on intestinal flora was not yet known, the intestinal flora is considered to play an important role through which $M$. charantia improves obesity and metabolic diseases (including diabetes) and is worth the sustained attention [54]. It was reported that BLSP (a bitter melon formulation) treatment reduced the ratio of Firmicutes and Bacteroidetes in the intestinal microflora of diabetic rats, while the relative abundance of Ruminococcaceae, Bacteroides, and Ruminococcus was significantly lower in BLSP-treated rats than in diabetic rats. These demonstrate that BLSP can alter the proportion of specific intestinal microflora in diabetic rats [55].

3.2.3. M. charantia Reduces Inflammatory Response in Diabetes Mellitus. M. charantia possesses antioxidant activities; it enhances the activity of superoxide dismutase, catalase, and nonprotein sulfhydryls and decreases lipid peroxidation. Moreover, M. charantia can inhibit the expression of proinflammatory cytokines (TNF- $\alpha$, IL- 6 , and IL-10), inflammatory markers (NO, inducible nitric oxide synthase, and myeloperoxidase), and apoptotic markers (BAX and caspase-3) and upregulate Bcl-2 expression [46]. By suppressing the activation of NF- $\kappa \mathrm{B}$ by inhibiting NF- $\kappa \mathrm{B}$ alpha $(\mathrm{I} \kappa \mathrm{B} \alpha)$ degradation and phosphorylation of JNK/p38 mitogenactivated protein kinases (JNK/p38 MAPKs), M. charantia can inhibit inflammation and improve the insulin signaling pathway, thereby ameliorating insulin resistance [54]. $M$. charantia has been reported to inhibit inflammation and the development of diabetes mellitus in rats and mice $[54,56]$. After weeks of treatment with $M$. charantia, fasting glucose, insulin, HOMA-IR index, serum lipid levels, fat cell size of epididymal adipose tissues, blood TNF- $\alpha$, IL-6, and
IL-10 levels, and local endotoxin levels decreased in highfat diet-induced obese rats [54]. Further studies have shown that $M$. charantia lowers mast cell recruitment in epididymal adipose tissues (EAT) and downregulates proinflammatory cytokines monocyte chemotactic protein-1 (MCP-1), IL-6, and TNF- $\alpha$ in EAT [56].

3.3. Curcumin. Curcumin is the active component of rhizomes of Curcuma longa, a plant in the ginger family. The chemical structure of curcumin is (1E,6E)-1,7-bis(4-hydroxy-3methoxyphenyl)hepta-1,6-diene-3,5-dione (Figure 2) [57]. Curcumin has been used as medicine for thousands of years. Recent years, extensive research on curcumin has found that curcumin has multiple biological activities, such as anticancer, anti-inflammation, antioxidation, antidiabetes, cardioprotective properties, and antiarthritis [58].

3.3.1. Effect of Curcumin on Diabetes. In different experimental animal models, such as rats with alloxan-, streptozotocin(STZ-), or STZ-nicotinamide-induced diabetes [59], oral administration of curcumin resulted in a reduction in body weight, blood glucose, and glycosylated hemoglobin levels [60] and improvement of insulin sensitivity [61]. In diabetic patients, curcumin treatment lowered blood levels of glycated hemoglobin (HbAlc) and fasting plasma glucose (FPG) and improved the pancreatic $\beta$ cell function, as indicated by homeostasis model assessment- $\beta$ (HOMA- $\beta$ ), C-peptide, and proinsulin/insulin ratio. Besides, curcumin can reduce the outcome of inflammatory cytokine [62] and improve relevant metabolic profiles in type 2 diabetic population [63].

3.3.2. Effect of Curcumin on Gut Microbiota and Mucosal Immunity. Curcumin changes the gut microbiota. Through high-throughput sequencing, at the phylum level, Spirochaetae, Tenericutes, and Elusimicrobia were decreased and Actinobacteria was increased after curcumin treatment. At the genus level, curcumin increased the abundance of Collinsella, Streptococcus, Sutterella, Gemella, Thalassospira, Gordonibacter, and Actinomyces [64].

Curcumin treatment can increase the protein expression of occludin and zonula occluden-1 (ZO-1), which maintain intestinal tight junction and regulate the permeability of the intestinal epithelial barrier $[16,65]$. Curcumin treatment also induces differentiation of naive $\mathrm{CD} 4^{+} \mathrm{T}$ cells into $\mathrm{CD}^{+} \mathrm{CD} 25^{+} \mathrm{Foxp}^{+}$Tregs and IL-10-producing $\operatorname{Tr} 1$ cells and increases the secretion of IL-10, TGF- $\beta$, and retinoic acid in the intestinal lamina propria [66]. Curcumin can also stimulate the intestinal epithelial cells and innate lymphoid cells to increase the secretion of IL-25, IL-33, IL-22, and IL-17 and play a role in anti-inflammatory activity [67].

\subsubsection{Curcumin Reduces Inflammatory Response in Diabetes.} Curcumin suppresses inflammation through complex mechanisms and multiple targets, such as inflammatory cytokines, protein kinases, and transcription factors. Inflammatory cytokines affected by curcumin include interleukins, TNF, IFN, and COX-2. Protein kinases include Janus kinase 1/2 (JAK1/2), JNK, extracellular signal-regulated kinase 1/2 (ERK1/2), IKK, and MAPK. Transcription factors include NF- $\kappa$ B [58]. 


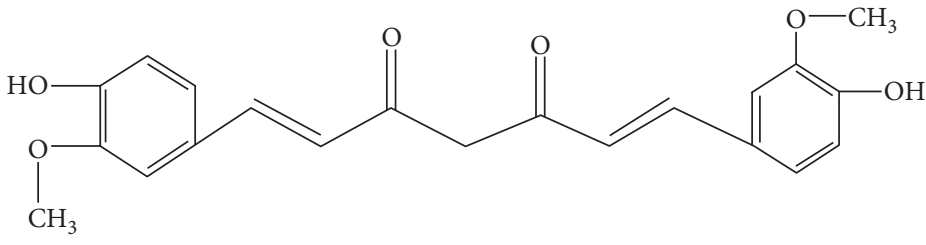

Figure 2: Molecular structure of curcumin.

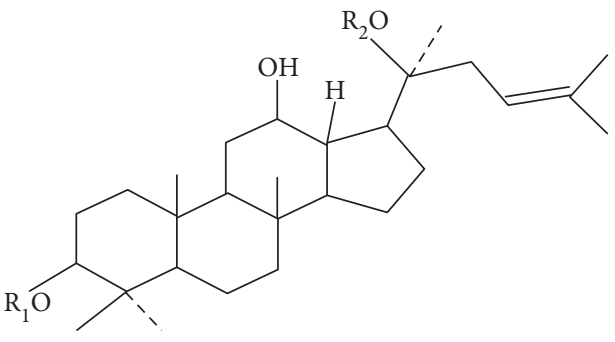

(a) Protopanaxadiol

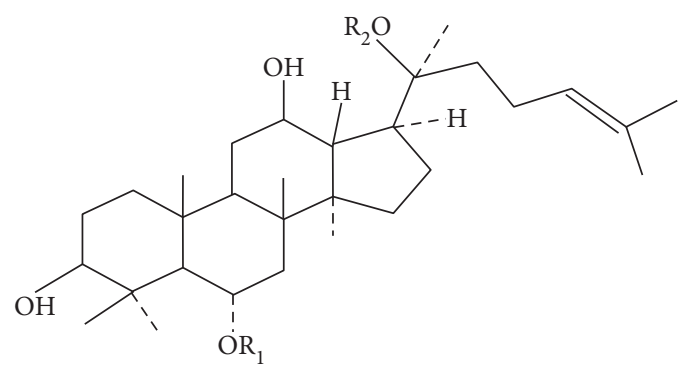

(b) Protopanaxatriol

FIGURE 3: Molecular structure of ginsenoside.

Curcumin can reduce the production of inducible nitric oxide synthase (iNOS) and cyclooxygenase- (COX-) 2 by inhibiting LPS-induced iNOS and COX-2 gene expression [68]. iNOS, as an inflammatory signaling factor, mediated inflammation by multiple pathways. Excessive expression of iNOS in cells causes the inflammation and insulin resistance of metabolic organs [69]. COX-2 is a key enzyme in the synthesis of prostaglandins, which contributes to lowgrade inflammation of tissues. It was found that curcumin exhibited anti-inflammatory activity by inhibiting the JNK/NF- $\kappa$ B activation and the gene expression of TNF- $\alpha$, IL-10, and IL-6 [70].

3.4. Ginsenoside. Panax ginseng has been used for centuries in TCM as an herbal remedy. It is one of the best chosen medical plants to replenish vitality/energy, nourish body fluid, and calm the nerves [71]. The active components of ginseng have been identified as a group of saponins called ginsenosides. According to the chemical structure, ginsenosides can be divided into ginseng diol saponins, ginseng triol saponins, and oleanolic acid saponins (Figure 3). Recent studies have shown that Panax ginseng and its monomers have a variety of pharmacologic action such as antioxidation [72, 73], antitumor [74], anti-inflammation [75, 76], immune regulation [77], antidiabetes [78, 79], and myocardial protection $[80,81]$. It can improve the immune system; inhibit inflammatory factors; protect cardiac function; lower blood glucose; inhibit rectal, liver, and breast cancers [74, 82, 83]; repair neurons; and delay the development of Parkinson's disease and Alzheimer's disease [84, 85].

3.4.1. Benefits of Ginsenosides to Diabetes. Studies have shown that ginsenoside $\mathrm{Rg} 1$ can improve glucose and lipid metabolisms and reduce blood glucose levels and insulin resistance indices in T2DM rats [86]. Ginsenoside Ge can improve hyperglycemia by improving cholinergic and antioxidant systems in the brain of C57BL/6 mice and improve high-fat diet-induced insulin resistance, reducing triglycerides and cholesterol [72]. Peroxisome proliferatoractivated receptors (PPARs) are transcription factors that play important roles in regulating glucose and lipid metabolisms and the development of atherosclerosis. A clinical study showed that ginsenosides could improve PPAR $\gamma$ expression and lipid metabolism, thereby reducing blood glucose [87]. Another study has shown that ginsenoside $\mathrm{Rb} 1$ activates the insulin signaling pathway, upregulates the expression and translocation of glucose transporters in adipose tissue, and thus increases glucose uptake in adipocytes, thereby reducing blood glucose levels and improving insulin resistance [88].

3.4.2. Ginsenoside Reduces the Inflammatory Response in Diabetes Mellitus. Studies have shown that inflammatory factors such as TNF- $\alpha$, IL- 6 , and monocyte chemoattractant protein-1 (MCP-1) interfere with the insulin signal transduction pathway and cause insulin resistance. They can also directly damage pancreatic $\beta$ cells [89-92]. It is reported that ginsenoside Rb1 reduces the expression of TNF- $\alpha$ and MCP-1 in 3T3-L1 cells through regulating the IKK/NF- $\kappa$ B signaling pathway $[93,94]$. In addition, ginsenoside $\mathrm{Rb} 1$ suppresses lipid accumulation and increases the lipolysis in 3T3-L1 adipocytes induced by TNF- $\alpha$ [94, 95]. Ginsenoside $\mathrm{Rb} 1$ reduced free fatty acids in the blood and fat content, improved lipid metabolism and insulin resistance, and inhibited TNF- $\alpha$, IL- 6 , and other inflammatory factors in obese mice [96-99].

3.5. Mulberry Leaf Extract (MLE). 1-Deoxynojirimycin (DNJ, Figure 4) and Kuwanon G (KWG, Figure 5) are the effective constituents of mulberry leaf, which belongs to the genus Morus of the Moraceae family. The chemical structure of DNJ is a glucose analogue with an $\mathrm{NH}$ group substituting for the oxygen atom of the pyranose ring 


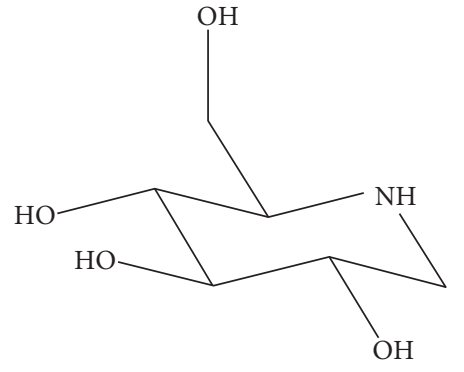

1-Deoxynojirimycin (DNJ)

FIgURE 4: Molecular structure of DNJ.<smiles>CC(C)=CCc1c(-c2ccc(O)cc2O)oc2c([C@@H]3C=C(C)C[C@H](c4ccc(O)cc4O)[C@H]3C(=O)c3ccc(O)cc3O)c(O)cc(O)c2c1=O</smiles>

Kuwanon G (KWG)

FIgURE 5: Molecular structure of KWG.

[100]. Mulberry leaf, as a traditional Chinese medicine, has been used to treat fever and inflammation for thousands of years. Recent research revealed that MLE have multiple biological activities, such as antidiabetes, antidyslipidemia, and anticancer [101].

3.5.1. Benefits of MLE to Diabetes. It is reported that 1deoxynojirimycin (DNJ) is an important component of MLE that is beneficial to the diabetes. In rats with STZ- or alloxan-induced diabetes, DNJ treatment markedly reduced blood levels of glucose and glycosylated hemoglobin and prevented the dysfunction of pancreatic $\beta$ cells $[102,103]$. A large number of studies have shown that DNJ is a competitive $\alpha$-glucosidase inhibitor, which is present in the intestinal epithelial cells. The function of this enzyme is to hydrolyze the disaccharides to monosaccharides for absorption. DNJ inhibits the glucose absorption through competitive inhibition of $\alpha$-glucosidase [104]. In $\mathrm{db} / \mathrm{db}$ mice, DNJ treatment improved insulin resistance via the activation of the insulin signaling PI3K/AKT pathway in skeletal muscle [100] and the activation of the $\mathrm{PKB} / \mathrm{GSK}-3 \beta$ signaling pathway in the liver [105].

3.5.2. Effects of MLE on the Intestinal Epithelial Barrier and Inflammation. Kuwanon G (KWG) which is essential in MLE is reported to protect the intestinal epithelial barrier. LPS can cause the disruption of the intestinal epithelial barrier and decrease the expression of intercellular junction protein. KWG treatment can increase the protein expression levels of occludin and intercellular adhesion molecule-1 [106].

Mulberry leaf has been used to treat fever and inflammation for thousands of years, and its extract also has antiinflammatory effects. A study showed that MLE inhibited the expression of inflammatory cytokines IL-I, IL-6, and TNF- $\alpha$ [107] and C-reactive protein (CRP) and MLE reduced the production of iNOS [108]. The decrease in inflammatory factors is indicative of reduced chronic inflammation and results in the improvement of insulin resistance.

3.6. Other Herbal Monomers. In addition to the five monomers described above, many other monomers are also found to be closely related to the BMID axis, including tetrandrine [109], notoginsenoside [110], Lycium barbarum polysaccharide [111], allicin [112], astragaloside IV [113, 114], quercetin [115], and resveratrol [116].

Among these monomers, astragaloside IV [117], quercetin [118], and resveratrol [119] affect gut microbiota, and notoginsenoside [120], Lycium barbarum polysaccharide [121], and allicin [122] affect the function of alleviating intestinal mucosal immunity; the anti-inflammatory monomers are tetrandrine [123], Lycium barbarum polysaccharide [124], allicin [125], astragaloside IV [126, 127], quercetin [128], resveratrol [116], and the effect and possible mechanism of these monomers are summarized in Table 1.

\section{Formulae}

A formula consists of multiple Chinese herbs, which are selected under the guidance of TCM theory. In the treatment of diabetes, a formula simultaneously affects multiple targets and regulates the homeostasis, and thus, the application of formulae attracted more focus. But the mechanism research of formulae is limited. The BMID axis will provide a new perspective and make it easier for further studies.

4.1. Gegen Qinlian Decoction (GGQLD). GGQLD has a very long history as a TCM formula, with the earliest record being found in the book Treatise on Febrile and Miscellaneous Diseases compiled by Zhongjing Zhang. GGQLD consists of extracts of Gegen (Puerariae lobataeradix), Huangqin (Scutellariae radix), Huanglian (Coptidis rhizoma), and Zhigancao (Glycyrrhizae radix et Rhizoma Praeparata cum Melle) [129]. In clinic, GGQLD is often used to treat ulcerative colitis and diabetes. Studies showed that GGQLD inhibits the inflammatory signaling pathway, enhances antioxidant effect, and thus improves ulcerative colitis. In addition, GGQLD improves glucose metabolism disorder, increases the insulin sensitivity index, and protects pancreatic $\beta$ cells, playing a positive role in the treatment of diabetes [130-132].

4.1.1. GGQLD Improves Diabetes. In some clinical observations and animal trials, GGQLD has been reported to have beneficial effects on diabetes. For example, in STZ- and HFD-induced diabetic SD rats, GGQLD significantly reduced FBG, $\mathrm{HbA1c}$, and insulin resistance index. In 3T3L1 adipocytes, GGQLD at $4 \%, 8 \%$, and $16 \%$ was found to 
TABLE 1: Chinese herbal products based on the BMID axis.

\begin{tabular}{|c|c|c|c|c|c|}
\hline \multirow{2}{*}{ Category } & \multirow{2}{*}{ Chinese herbal products } & \multicolumn{4}{|c|}{ "BMID" axis } \\
\hline & & Bacteria & Mucosal immunity & Inflammation & Diabetes \\
\hline \multirow{13}{*}{ Monomers } & Berberine & + & + & + & + \\
\hline & M. charantia extract & + & & + & + \\
\hline & Curcumin & + & + & + & + \\
\hline & Ginsenoside & & + & + & + \\
\hline & 1-Deoxynojirimycin & & & + & + \\
\hline & Kuwanon G & & + & & + \\
\hline & Tetrandrine & & & + & + \\
\hline & Notoginsenoside & & + & & + \\
\hline & Lycium barbarum polysaccharide & & + & + & + \\
\hline & Allicin & & + & + & + \\
\hline & Astragaloside IV & + & & & + \\
\hline & Quercetin & + & & + & + \\
\hline & Resveratrol & + & & + & + \\
\hline \multirow{3}{*}{ Formulae } & GGQLD & + & + & + & + \\
\hline & DGLHD & & + & + & + \\
\hline & HLWDD & & & + & + \\
\hline
\end{tabular}

"+" means positive effect while the "blank" means no effect. GGQLD: Gegen Qinlian Decoction; DGLHD: Danggui Liuhuang Decoction; HLWDD: Huanglian Wendan Decoction.

increase glucose consumption and decrease triglyceride in a dose-dependent manner [131]. In an observational study, T2DM patients treated with a high dose of modified GGQLD reduced blood $\mathrm{HbAlc}$ to $1.79 \%$ from the initial level of $9.2 \%$ [4]. Although limited, available information has demonstrated that GGQLD is beneficial to glucose metabolism and homeostasis.

4.1.2. GGQLD Alters Gut Microbiota. There is an established connection between an altered gut microbiota and metabolic disorders such as obesity and diabetes [133, 134]. After treatment with GGQLD, the relative abundance of intestinal beneficial bacteria such as Lachnospiracea incertae sedis, Gemmiger, Bifidobacterium, and Faecalibacterium was significantly higher while harmful bacteria such as $F$. prausnitzii, Alistipes, Pseudobutyrivibrio, and Parabacteroides decreased. GGQLD increases butyrate production and protects the integrity of the mucosal barriers, thereby exerting antiinflammatory effects which are beneficial to diabetes [135]. A study showed that GGQLD induces compositional changes in the intestinal microflora, increases beneficial bacteria, such as Faecalibacterium spp., and thus exerts an antidiabetic effect [135].

4.2. Danggui Liuhuang Decoction (DGLHD). DGLHD is an old Chinese herbal formula which comes from the book Lan Shi Mi Cang written by Gao Li 741 years ago. DGLHD prescription consists of Dangui (Angelica sinensis), Shengdihuang (Radix rehmanniae preparata), Huangqin (Radix scutellariae), Huanglian (Rhizoma coptidis), Huangbo (Cortex phellodendri), and Huangqi (Radix astragali). Researches indicate that DGLHD decreases FBG and HbAlc levels and protects pancreatic $\beta$ cells [136].
Recent studies have demonstrated that DGLHD possesses antidiabetic and immunomodulatory effects. For instance, DGLHD enhances glucose uptake in HepG2 cells, inhibits $\mathrm{T}$ lymphocyte proliferation, and suppresses the function of dendritic cells. After 16 weeks of treatment, DGLHD promotes insulin secretion, increases insulin sensitivity, and decreases the range of lymphocyte infiltration to inhibit insulitis as well as to protect pancreatic $\beta$ cells in NOD mice [137].

DGLHD inhibited LPS-induced production of NO and IL-6 and the expression of iNOS and COX-2. Furthermore, DGLHD suppressed LPS-induced phosphorylation of ERK1/2 [138]. $\mathrm{CD}^{+} \mathrm{CD} 25^{+} \mathrm{Foxp}^{+}{ }^{+}$Tregs exhibit immune regulatory activity and protect against autoimmune diabetes development. With oral intake of DGLHD, forkhead box transcription factor (Foxp3) mRNA expression in the pancreas and spleen increased. Foxp3 is essential for the differentiation and function of Tregs; thus, DGLHD increases the percentage of $\mathrm{CD}^{+} \mathrm{CD} 25^{+} \mathrm{Foxp}^{+}$Tregs in spleen lymphocytes, therefore inhibiting the low-grade inflammation in the pancreas. DGLHD also regulates the maturation and function of dendritic cells, increasing the expression of programmed death ligand-1 and decreasing the percentage of merocytic dendritic cell subset, which in turn decreases $\mathrm{T}$ cell-mediated inflammation and ameliorates diabetes [137].

4.3. Huanglian Wendan Decoction (HLWDD). HLWDD is a Chinese herbal formula recorded in the book Liu Yin Tiao Bian [139]. It consists of root and rhizome of Coptis deltoidea C. Y. Cheng \& P. K. Hsiao (family: Ranunculaceae), cortex of Bambusa textilis McClure (family: Poaceae), caulis of Pinellia ternata (Thunb.) Makino (family: Araceae), fructus of Citrus aurantium L. (family: Rutaceae), pericarpium of Citrus 
reticulata Blanco (family: Rutaceae), dried sclerotia of Poria $\operatorname{cocos}$ (Schw.) Wolf (family: Polyporaceae), root and rhizome of Glycyrrhiza uralensis Fisch (family: Leguminosae), and root and rhizome of Zingiber officinale Roscoe (family: Zingiberaceae). It has been used clinically to treat diabetes and its complications [140].

A recent study showed that treatment with HLWDD ( $6 \mathrm{~g} \cdot \mathrm{kg}^{-1}$ body weight) for 30 days increased the body weight and decreased FBG, triglycerides, and cholesterol compared with the diabetic model group. HLWDD decreases the release of proinflammatory cytokines, such as TNF- $\alpha$, IL-6, and IL- $1 \beta$, and inhibits the phosphorylation of IRS1 at the Ser307 and JNK signal pathway. Through these mechanisms, HLWDD inhibits inflammatory responses and thus improves the insulin signaling pathway [141].

\section{Conclusions}

Diabetes and its complications seriously affect human health and impose increasingly a heavy burden on the health care in many countries. Chinese herbs are inexpensive, less toxic, and tolerable than drugs. Therefore, they have been attracting increased attention in the field of diabetic prevention and treatment. Although clinical efficacy of Chinese herbs or herbal formulae is supported by emerging evidence, the mechanism is still lacking.

Through the analysis of a large number of studies on diabetic pathogenesis and treatment, we proposed the "BacteriaMucosal Immunity-Inflammation-Diabetes" (BMID) axis through which we attempted to explain how herbal monomers and formulae improve diabetes. Evidence has demonstrated that monomers and formulae improve diabetes and insulin function via multiple targets. Moreover, the majority of the current studies of TCM on diabetes were focused on inflammation and limited gut microbiota and intestinal mucosal immunity. Furthermore, most studies were aimed to a single target.

Functional food and natural health products have been of great interest to patients, doctors, and researchers for over a decade. Chinese herbs and herbal products are critical and a rich resource of information for the development of health products and precision medicine. Although increasing scientific evidence has been generated from clinical, preclini$\mathrm{cal}$, and in vitro studies, the information is still limited and lacks systemic evaluation. The mechanisms of action are particularly a weak area that needs an increased attention. BMID is our first attempt to integrate information and results of various studies and inspire a focus of future direction at which future studies can be conducted to support and improve it. We hope that this review will provide new perspectives and strategies for future research on Chinese herbal products for the prevention and treatment of diabetes and further product development.

\section{Conflicts of Interest}

The authors declare that they have no competing interests.

\section{Authors' Contributions}

Zezheng Gao and Qingwei $\mathrm{Li}$ contributed equally to this work.

\section{References}

[1] Y. Zhang, X. Li, D. Zou et al., "Treatment of type 2 diabetes and dyslipidemia with the natural plant alkaloid berberine," The Journal of Clinical Endocrinology and Metabolism, vol. 93, no. 7, pp. 2559-2565, 2008.

[2] L. Ji, X. Tong, H. Wang et al., "Efficacy and safety of traditional Chinese medicine for diabetes: a double-blind, randomised, controlled trial," PLoS One, vol. 8, no. 2, 2013.

[3] X. L. Tong, S. T. Wu, F. M. Lian et al., "The safety and effectiveness of TM81, a Chinese herbal medicine, in the treatment of type 2 diabetes: a randomized double-blind placebo-controlled trial," Diabetes, Obesity \& Metabolism, vol. 15, no. 5, pp. 448-454, 2013.

[4] X. L. Tong, L. H. Zhao, F. M. Lian et al., "Clinical observations on the dose-effect relationship of Gegen Qin Lian decoction on 54 out-patients with type 2 diabetes," Journal of Traditional Chinese Medicine, vol. 31, no. 1, pp. 56-59, 2011.

[5] B. Godman, R. E. Malmström, E. Diogene et al., "Are new models needed to optimize the utilization of new medicines to sustain healthcare systems?," Expert Review of Clinical Pharmacology, vol. 8, no. 1, pp. 77-94, 2015.

[6] J. E. Shaw, R. A. Sicree, and P. Z. Zimmet, "Global estimates of the prevalence of diabetes for 2010 and 2030," Diabetes Research and Clinical Practice, vol. 87, no. 1, pp. 4-14, 2010.

[7] H. Cai, G. Li, P. Zhang, D. Xu, and L. Chen, "Effect of exercise on the quality of life in type 2 diabetes mellitus: a systematic review," Quality of Life Research, vol. 26, no. 3, pp. 515530, 2017.

[8] S. R. Gill, M. Pop, R. T. Deboy et al., "Metagenomic analysis of the human distal gut microbiome," Science, vol. 312, no. 5778, pp. 1355-1359, 2006.

[9] R. E. Ley, F. Bäckhed, P. Turnbaugh, C. A. Lozupone, R. D. Knight, and J. I. Gordon, "Obesity alters gut microbial ecology," Proceedings of the National Academy of Sciences of the United States of America, vol. 102, no. 31, pp. 11070-11075, 2005.

[10] P. D. Cani, A. M. Neyrinck, F. Fava et al., "Selective increases of bifidobacteria in gut microflora improve high-fat-dietinduced diabetes in mice through a mechanism associated with endotoxaemia," Diabetologia, vol. 50, no. 11, pp. 23742383, 2007.

[11] J. Qin, Y. Li, Z. Cai et al., "A metagenome-wide association study of gut microbiota in type 2 diabetes," Nature, vol. 490, no. 7418, pp. 55-60, 2012.

[12] E. Le Chatelier, T. Nielsen, J. Qin et al., "Richness of human gut microbiome correlates with metabolic markers," Nature, vol. 500, no. 7464, pp. 541-546, 2013.

[13] M. A. Odenwald and J. R. Turner, "The intestinal epithelial barrier: a therapeutic target?," Nature Reviews Gastroenterology \& Hepatology, vol. 14, no. 1, pp. 9-21, 2017.

[14] J. Amar, C. Chabo, A. Waget et al., "Intestinal mucosal adherence and translocation of commensal bacteria at the early onset of type 2 diabetes: molecular mechanisms and probiotic treatment," EMBO Molecular Medicine, vol. 3, no. 9, pp. 559-572, 2011. 
[15] P. D. Cani, J. Amar, M. A. Iglesias et al., "Metabolic endotoxemia initiates obesity and insulin resistance," Diabetes, vol. 56, no. 7, pp. 1761-1772, 2007.

[16] P. D. Cani, R. Bibiloni, C. Knauf et al., "Changes in gut microbiota control metabolic endotoxemia-induced inflammation in high-fat diet-induced obesity and diabetes in mice," Diabetes, vol. 57, no. 6, pp. 1470-1481, 2008.

[17] F. R. Costa, M. C. Françozo, G. G. de Oliveira et al., "Gut microbiota translocation to the pancreatic lymph nodes triggers NOD2 activation and contributes to T1D onset," The Journal of Experimental Medicine, vol. 213, no. 7, pp. 1223-1239, 2016.

[18] S. Fukuda, H. Toh, K. Hase et al., "Bifidobacteria can protect from enteropathogenic infection through production of acetate," Nature, vol. 469, no. 7331, pp. 543-547, 2011.

[19] C. L. Maynard, C. O. Elson, R. D. Hatton, and C. T. Weaver, "Reciprocal interactions of the intestinal microbiota and immune system," Nature, vol. 489, no. 7415, pp. 231-241, 2012.

[20] L. Garidou, C. Pomié, P. Klopp et al., "The gut microbiota regulates intestinal CD4 $\mathrm{T}$ cells expressing RORgt and controls metabolic disease," Cell Metabolism, vol. 22, no. 1, pp. 100-112, 2015.

[21] M. Kassan, S. K. Choi, M. Galán et al., "Enhanced NF- $\kappa B$ activity impairs vascular function through PARP-1-, SP-1-, and COX-2-dependent mechanisms in type 2 diabetes," Diabetes, vol. 62, no. 6, pp. 2078-2087, 2013.

[22] I. Hameed, S. R. Masoodi, S. A. Mir, M. Nabi, K. Ghazanfar, and B. A. Ganai, "Type 2 diabetes mellitus: from a metabolic disorder to an inflammatory condition," World Journal of Diabetes, vol. 6, no. 4, pp. 598-612, 2015.

[23] Z. T. Bloomgarden, "Inflammation and insulin resistance," Diabetes Care, vol. 26, no. 6, pp. 1922-6, 2003.

[24] I. A. Zolotnik and T. Y. Figueroa, "Insulin receptor and IRS-1 co-immunoprecipitation with SOCS-3, and $\mathrm{IKK} \alpha / \beta$ phosphorylation are increased in obese Zucker rat skeletal muscle," Life Sciences, vol. 91, no. 15-16, p. 816, 2012.

[25] X. Jin, X. Song, Y. B. Cao, Y. Y. Jiang, and Q. Y. Sun, "Research progress in structural modification and pharmacological activities of berberine," Journal of Pharmacy Practice, vol. 32, pp. 171-175, 2014.

[26] H. Zhou, L. Feng, F. Xu et al., "Berberine inhibits palmitateinduced NLRP3 inflammasome activation by triggering autophagy in macrophages: a new mechanism linking berberine to insulin resistance improvement," Biomedicine \& Pharmacotherapy, vol. 89, pp. 864-874, 2017.

[27] L. M. Ortiz, P. Lombardi, M. Tillhon, and A. Scovassi, "Berberine, an epiphany against cancer," Molecules, vol. 19, pp. 12349-12367, 2014

[28] Y. Sun, K. Xun, Y. Wang, and X. Chen, "A systematic review of the anticancer properties of berberine: a natural product from Chinese herbs," Anti-Cancer Drugs, vol. 13, pp. 757769, 2009.

[29] J. Tang, Y. Feng, S. Tsao, N. Wang, R. Curtain, and Y. Wang, "Berberine and Coptidis rhizoma as novel antineoplastic agents: a review of traditional use and biomedical investigations," Journal of Ethnopharmacology, vol. 13, pp. 5-17, 2009.

[30] M. Ming, J. Sinnett-Smith, J. Wang et al., "Dose-dependent AMPK-dependent and independent mechanisms of berberine and metformin inhibition of mTORC1, ERK, DNA synthesis and proliferation in pancreatic cancer cells," PLoS One, vol. 9, no. 12, 2014.

[31] P. Jabbarzadeh Kaboli, A. Rahmat, P. Ismail, and K. H. Ling, "Targets and mechanisms of berberine, a natural drug with potential to treat cancer with special focus on breast cancer," European Journal of Pharmacology, vol. 740, pp. 584-595, 2014.

[32] B. Vandanmagsar, Y. H. Youm, A. Ravussin et al., "The NLRP3 inflammasome instigates obesity-induced inflammation and insulin resistance," Nature Medicine, vol. 17, no. 2, pp. 179-188, 2011.

[33] L. Ye, L. Shu, G. Chao et al., "Inhibition of M1 macrophage activation in adipose tissue by berberine improves insulin resistance," Life Sciences, vol. 166, pp. 82-91, 2016.

[34] X. Wang, N. Ota, P. Manzanillo et al., "Interleukin-22 alleviates metabolic disorders and restores mucosal immunity in diabetes," Nature, vol. 514, no. 7521, pp. 237-241, 2014.

[35] J. Gong, M. Hu, Z. Huang et al., "Berberine attenuates intestinal mucosal barrier dysfunction in type 2 diabetic rats," Frontiers in Pharmacology, vol. 3, no. 8, p. 42, 2017.

[36] J. H. Xu, X. Z. Liu, W. Pan, and D. J. Zou, "Berberine protects against diet-induced obesity through regulating metabolic endotoxemia and gut hormone levels," Molecular Medicine Reports, vol. 15, no. 5, pp. 2765-2787, 2017.

[37] H. Sun, N. Wang, C. Zhen et al., "Modulation of microbiotagut-brain axis by berberine resulting in improved metabolic status in high-fat diet-fed rats," Obesity Facts, vol. 9, no. 6, p. $365,2016$.

[38] C. Mo, L. Wang, J. Zhang et al., "The crosstalk between Nrf2 and AMPK signal pathways is important for the antiinflammatory effect of berberine in LPS-stimulated macrophages and endotoxin-shocked mice," Antioxidants \& Redox Signaling, vol. 20, no. 4, pp. 574-588, 2014.

[39] B.-H. Choi, I.-S. Ahn, Y.-H. Kim et al., "Berberine reduces the expression of adipogenic enzymes and inflammatory molecules of 3T3-L1 adipocyte," Experimental and Molecular Medicine, vol. 38, no. 6, pp. 599-605, 2006.

[40] T. Lou, Z. Zhang, Z. Xi et al., "Berberine inhibits inflammatory response and ameliorates insulin resistance in hepatocytes," Inflammation, vol. 34, no. 6, pp. 659-667, 2011.

[41] Y. Wang, "Attenuation of berberine on lipopolysaccharideinduced inflammatory and apoptosis responses in $\beta$-cells via TLR4-independent JNK/NF- $\kappa$ B pathway," Pharmaceutical Biology, vol. 52, no. 4, 2013.

[42] G. Cui, X. Qin, Y. Zhang, Z. Gong, B. Ge, and Y. Q. Zang, "Berberine differentially modulates the activities of ERK, p38 MAPK, and JNK to suppress Th17 and Th1 T cell differentiation in type 1 diabetic mice," The Journal of Biological Chemistry, vol. 284, no. 41, pp. 28420-28429, 2009.

[43] W.-H. Chueh and J.-Y. Lin, "Protective effect of isoquinoline alkaloid berberine on spontaneous inflammation in the spleen, liver and kidney of non-obese diabetic mice through downregulating gene expression ratios of pro-/anti-inflammatory and Th1/Th2 cytokines," Food Chemistry, vol. 131, no. 4, pp. 1263-1271, 2012.

[44] N. P. Fernandes, C. V. Lagishetty, V. S. Panda, and S. R. Naik, "An experimental evaluation of the antidiabetic and antilipidemic properties of a standardized Momordica charantia fruit extract," BMC Complementary and Alternative Medicine, vol. 7, p. 29, 2007. 
[45] J. S. Yu, J. H. Kim, S. Lee, K. Jung, K. H. Kim, and J. Y. Cho, "Src/Syk-targeted anti-inflammatory actions of triterpenoidal saponins from Gac (Momordica cochinchinensis) seeds," The American Journal of Chinese Medicine, vol. 2, pp. 1-15, 2017.

[46] M. Raish, "Momordica charantia polysaccharides ameliorate oxidative stress, hyperlipidemia, inflammation, and apoptosis during myocardial infarction by inhibiting the NF- $\kappa \mathrm{B}$ signaling pathway," International Journal of Biological Macromolecules, vol. 97, pp. 544-551, 2017.

[47] P. Khanna, S. C. Jain, A. Panagariya, and V. P. Dixit, "Hypoglycemic activity of polypeptide-p from a plant source," Journal of Natural Products, vol. 44, pp. 648-655, 1981.

[48] M. F. Mahmoud, F. E. El Ashry, N. N. El Maraghy, and A. Fahmy, "Studies on the antidiabetic activities of Momordica charantia fruit juice in streptozotocin-induced diabetic rats," Pharmaceutical Biology, vol. 55, no. 1, pp. 758-765, 2017.

[49] M. B. Krawinkel and G. B. Keding, "Bitter gourd (Momordica charantia): a dietary approach to hyperglycemia," Nutrition Reviews, vol. 64, pp. 331-337, 2006.

[50] P. Chaturvedi, "Antidiabetic potentials of Momordica charantia: multiple mechanisms behind the effects," Journal of Medicinal Food, vol. 15, no. 2, p. 101, 2012.

[51] A. Fuangchan, P. Sonthisombat, T. Seubnukarn et al., "Hypoglycemic effect of bitter melon compared with metformin in newly diagnosed type 2 diabetes patients," Journal of Ethnopharmacology, vol. 134, no. 2, pp. 422-428, 2011.

[52] E. Basch, S. Gabardi, and C. Ulbricht, "Bitter melon (Momordica charantia): a review of efficacy and safety," American Journal of Health-System Pharmacy, vol. 60, pp. 356-359, 2003.

[53] H. Hui, G. Tang, and V. L. W. Go, "Hypoglycemic herbs and their action mechanisms," Chinese Medicine, vol. 4, no. 1, p. 11, 2009.

[54] J. Bai, Y. Zhu, and Y. Dong, "Response of gut microbiota and inflammatory status to bitter melon (Momordica charantia L.) in high fat diet induced obese rats," Journal of Ethnopharmacology, vol. 194, pp. 717-726, 2016.

[55] Y. Zhu, J. Bai, Y. Zhang, X. Xiao, and Y. Dong, "Effects of bitter melon (Momordica charantia L.) on the gut microbiota in high fat diet and low dose streptozocin-induced rats," International Journal of Food Sciences \& Nutrition, vol. 67, no. 6, p. 686, 2016.

[56] B. Bao, Y. G. Chen, L. Zhang et al., "Momordica charantia (bitter melon) reduces obesity-associated macrophage and mast cell infiltration as well as inflammatory cytokine expression in adipose tissues," PLoS One, vol. 8, no. 12, article e84075, 2013.

[57] A. S. Pithadia, A. Bhunia, R. Sribalan, V. Padmini, C. A. Fierke, and A. Ramamoorthy, "Influence of a curcumin derivative on hIAPP aggregation in the absence and presence of lipid membranes," Chemical Communications (Camb), vol. 52, no. 5, pp. 942-945, 2016.

[58] S. Prasad, S. C. Gupta, A. K. Tyagi, and B. B. Aggarwal, "Curcumin, a component of golden spice: from bedside to bench and back," Biotechnology Advances, vol. 32, no. 6, pp. 1053-1064, 2014.

[59] L. Pari and P. Murugan, "Tetrahydrocurcumin prevents brain lipid peroxidation in streptozotocin-induced diabetic rats," Journal of Medicinal Food, vol. 10, pp. 323-329, 2007.
[60] N. Arun and N. Nalini, "Efficacy of turmeric on blood sugar and polyol pathway in diabetic albino rats," Plant Foods for Human Nutrition, vol. 57, pp. 41-52, 2002.

[61] P. Murugan and L. Pari, "Influence of tetrahydrocurcumin on hepatic and renal functional markers and protein levels in experimental type 2 diabetic rats," Basic \& Clinical Pharmacology \& Toxicology, vol. 101, pp. 241-245, 2007.

[62] S. Chuengsamarn, S. Rattanamongkolgul, R. Luechapudiporn, C. Phisalaphong, and S. Jirawatnotai, "Curcumin extract for prevention of type 2 diabetes," Diabetes Care, vol. 35, no. 11, pp. 2121-2127, 2012.

[63] S. Chuengsamarn, S. Rattanamongkolgul, and B. Phonrat, "Reduction of atherogenic risk in patients with type 2 diabetes by curcuminoid extract: a randomized controlled trial," The Journal of Nutritional Biochemistry, vol. 25, pp. 144150, 2014.

[64] W. Feng, H. Wang, P. Zhang et al., "Modulation of gut microbiota contributes to curcumin-mediated attenuation of hepatic steatosis in rats," Biochimica et Biophysica Acta, vol. 1861, no. 7, pp. 1801-1812, 2017.

[65] R. Al-Sadi, S. Guo, D. Ye, and T. Y. Ma, “TNF-alpha modulation of intestinal epithelial tight junction barrier is regulated by ERK1/2 activation of Elk-1," The American Journal of Pathology, vol. 183, pp. 1871-1884, 2013.

[66] Y. Cong, L. Wang, A. Konrad, T. Schoeb, and C. O. Elson, "Curcumin induces the tolerogenic dendritic cell that promotes differentiation of intestine-protective regulatory T cells," European Journal of Immunology, vol. 39, no. 11, pp. 3134-3146, 2009.

[67] J. Wang, S. S. Ghosh, and S. Ghosh, "Curcumin improves intestinal barrier function: modulation of intracellular signaling and 2 organization of tight junctions," American Journal of Physiology - Cell Physiology, vol. 312, no. 4, pp. C438C445, 2017.

[68] S. Gafner, S. K. Lee, M. Cuendet et al., "Biologic evaluation of curcumin and structural derivatives in cancer chemoprevention model systems," Phytochemistry, vol. 65, pp. 2849-2859, 2004.

[69] K. M. Sakthivel and C. Guruvayoorappan, "Acacia ferruginea inhibits inflammation by regulating inflammatory iNOS and COX-2," Journal of Immunotoxicology, vol. 13, no. 1, pp. 127-135, 2016.

[70] Y. Pan, Y. Wang, L. Cai et al., "Inhibition of high glucoseinduced inflammatory response and macrophage infiltration by a novel curcumin derivative prevents renal injury in diabetic rats," British Journal of Pharmacology, vol. 166, no. 3, pp. 1169-1182, 2012.

[71] J. Yin, H. Zhang, and J. Ye, "Traditional Chinese medicine in treatment of metabolic syndrome," Endocrine Metabolic \& Immune Disorders Drug Targets, vol. 8, no. 2, p. 99, 2008.

[72] J. M. Kim, C. H. Park, S. K. Park et al., "Ginsenoside Re ameliorates brain insulin resistance and cognitive dysfunction in high-fat diet-induced C57BL/6 mice," Journal of Agricultural \& Food Chemistry, vol. 65, no. 13, pp. 27192729, 2017.

[73] C. Lu, Z. Shi, L. Dong et al., "Exploring the effect of ginsenoside Rh1 in a sleep deprivation-induced mouse memory impairment model," Phytotherapy Research (PTR), vol. 31, no. 5, pp. 763-770, 2017.

[74] D. Dai, C. F. Zhang, S. Williams, C. S. Yuan, and C. Z. Wang, "Ginseng on cancer: potential role in modulating 
inflammation-mediated angiogenesis," American Journal of Chinese Medicine, vol. 45, no. 1, pp. 13-22, 2017.

[75] I. S. Lee, I. J. Uh, K. S. Kim et al., "Anti-inflammatory effects of ginsenoside Rg3 via NF- $\kappa$ B pathway in A549 cells and human asthmatic lung tissue," Journal of Immunology Research, vol. 2016, Article ID 7521601, 11 pages, 2016.

[76] S. Ahn, M. H. Siddiqi, V. C. Aceituno, S. Y. Simu, and D. C. Yang, "Suppression of MAPKs/NF- $\kappa \mathrm{B}$ activation induces intestinal anti-inflammatory action of ginsenoside $\mathrm{Rf}$ in HT-29 and RAW264.7 cells," Immunological Investigations, vol. 45, no. 5, p. 439, 2016.

[77] S. Bao, Z. Yun, W. Bing et al., "Ginsenoside Rg1 improves lipopolysaccharide-induced acute lung injury by inhibiting inflammatory responses and modulating infiltration of M2 macrophages," International Immunopharmacology, vol. 28, no. 1, pp. 429-434, 2015.

[78] Q. T. Bu, W. Y. Zhang, Q. C. Chen et al., "Anti-diabetic effect of ginsenoside $\mathrm{Rb}(3)$ in alloxan-induced diabetic mice," Medicinal Chemistry, vol. 8, no. 5, pp. 934-941, 2012.

[79] Y. C. Hwang, D. H. Oh, M. C. Choi et al., "Compound $\mathrm{K}$ attenuates glucose intolerance and hepatic steatosis through AMPK-dependent pathways in type 2 diabetic OLETF rats," Korean Journal of Internal Medicine, 2017.

[80] Y. J. Zhang, X. L. Zhang, M. H. Li et al., “The ginsenoside Rg1 prevents transverse aortic constriction-induced left ventricular hypertrophy and cardiac dysfunction by inhibiting fibrosis and enhancing angiogenesis," Journal of Cardiovascular Pharmacology, vol. 62, no. 1, p. 50, 2013.

[81] H. Yu, J. Zhen, Y. Yang, J. Gu, S. Wu, and Q. Liu, "Ginsenoside Rg1 ameliorates diabetic cardiomyopathy by inhibiting endoplasmic reticulum stress-induced apoptosis in a streptozotocin-induced diabetes rat model," Journal of Cellular \& Molecular Medicine, vol. 20, no. 4, p. 623, 2016.

[82] L. U. Ping, S. U. Wei, Z. H. Miao, H. R. Niu, J. Liu, and Q. L. Hua, "Effect and mechanism of ginsenoside Rg3 on postoperative life span of patients with non-small cell lung cancer," Chinese Journal of Integrative Medicine, vol. 14, no. 1, pp. 33-36, 2008.

[83] Z. Yuan, H. Jiang, X. Zhu, X. Liu, and J. Li, "Ginsenoside Rg3 promotes cytotoxicity of paclitaxel through inhibiting NF- $\kappa \mathrm{B}$ signaling and regulating $\mathrm{Bax} / \mathrm{Bcl}-2$ expression on triplenegative breast cancer," Biomedicine \& Pharmacotherapy, vol. 89, pp. 227-232, 2017.

[84] X. Zhang, Y. Wang, C. Ma et al., "Ginsenoside Rd and ginsenoside Re offer neuroprotection in a novel model of Parkinson's disease," American Journal of Neurodegenerative Disease, vol. 5, no. 1, p. 52, 2016.

[85] F. Li, X. Wu, J. Li, and Q. Niu, "Ginsenoside Rg1 ameliorates hippocampal long-term potentiation and memory in an Alzheimer's disease model," Molecular Medicine Reports, vol. 13, no. 6, p. 4904,2016

[86] W. Tian, L. Chen, L. Zhang et al., "Effects of ginsenoside Rg1 on glucose metabolism and liver injury in streptozotocininduced type 2 diabetic rats," Genetics \& Molecular Research Gmr, vol. 16, no. 1, 2017.

[87] H. X. Ni, N. J. Yu, and X. H. Yang, "The study of ginsenoside on PPARgamma expression of mononuclear macrophage in type 2 diabetes," Molecular Biology Reports, vol. 37, no. 6, p. 2975, 2010.

[88] W. B. Shang, C. Guo, J. Zhao, X. Z. Yu, and H. Zhang, "Ginsenoside Rb1 upregulates expressions of GLUTs to promote glucose consumption in adiopcytes," Zhongguo Zhong Yao Za Zhi, vol. 39, no. 22, p. 448, 2014.

[89] K. Waugh, J. Snellbergeon, A. Michels et al., "Increased inflammation is associated with islet autoimmunity and type 1 diabetes in the Diabetes Autoimmunity Study in the Young (DAISY)," PLoS One, vol. 12, no. 4, article e0174840, 2017.

[90] J. Z. Q. Luo, J. W. Kim, and L. Luo, "Effects of ginseng and its four purifed ginsenosides (Rb2, Re, Rg1, Rd) on human pancreatic islet $\beta$ cell in vitro," European Journal Pharmaceutical \& Medical Research, vol. 3, no. 1, p. 110, 2016.

[91] S. S. Kim, H. J. Jang, M. Y. Oh et al., "Ginsenoside Rg3 enhances islet cell function and attenuates apoptosis in mouse islets," Transplantation Proceedings, vol. 46, no. 4, pp. 1150-1155, 2014.

[92] K. Eguchi and R. Nagai, "Islet inflammation in type 2 diabetes and physiology," Journal of Clinical Investigation, vol. 127, no. 1, p. 14, 2017.

[93] W. Shang, Y. Yang, L. Zhou, B. Jiang, H. Jin, and M. Chen, "Ginsenoside Rb1 stimulates glucose uptake through insulin-like signaling pathway in 3T3-L1 adipocytes," Journal of Endocrinology, vol. 198, no. 3, p. 561, 2008.

[94] Q. Mu, X. Fang, X. Li et al., "Ginsenoside Rb1 promotes browning through regulation of PPAR $\gamma$ in 3T3-L1 adipocytes," Biochemical \& Biophysical Research Communications, vol. 466, no. 3, pp. 530-535, 2015.

[95] Y. Gao, M. F. Yang, Y. P. Su et al., "Ginsenoside Re reduces insulin resistance through activation of PPAR- $\gamma$ pathway and inhibition of TNF- $\alpha$ production," Journal of Ethnopharmacology, vol. 147, no. 2, pp. 509-516, 2013.

[96] L. Zhang, L. Zhang, X. Wang, and H. Si, “Anti-adipogenic effects and mechanisms of ginsenoside Rg3 in preadipocytes and obese mice," Frontiers in Pharmacology, vol. 8, p. 113, 2017.

[97] Y. Wu, Y. Yu, A. Szabo, M. Han, and X. F. Huang, "Central inflammation and leptin resistance are attenuated by ginsenoside Rb1 treatment in obese mice fed a high-fat diet," PLoS One, vol. 9, no. 3, 2014.

[98] X. M. Zhang, S. C. Qu, D. Y. Sui, X. F. Yu, and Z. Z. Lv, "Effects of ginsenoside-Rb on blood lipid metabolism and anti-oxidation in hyperlipidemia rats," China Journal of Chinese Materia Medica, vol. 29, no. 11, pp. 10851088, 2004.

[99] S. Yu, X. Zhou, F. Li et al., "Microbial transformation of ginsenoside $\mathrm{Rb} 1, \mathrm{Re}$ and $\mathrm{Rg} 1$ and its contribution to the improved anti-inflammatory activity of ginseng," Scientific Reports, vol. 7, no. 1, p. 138, 2017.

[100] Q. Liu, X. Li, C. Li, Y. Zheng, and G. Peng, "1-Deoxynojirimycin alleviates insulin resistance via activation of insulin signaling PI3K/AKT pathway in skeletal muscle of $\mathrm{db} / \mathrm{db}$ mice," Molecules, vol. 20, no. 12, pp. 21700-21714, 2015.

[101] Y. Liu, X. Li, C. Xie et al., "Prevention effects and possible molecular mechanism of mulberry leaf extract and its formulation on rats with insulin-insensitivity," PLoS One, vol. 11, no. 4, 2016.

[102] V. Saini, "Molecular mechanisms of insulin resistance in type 2 diabetes mellitus," World Journal of Diabetes, vol. 1, no. 3, pp. 68-75, 2010.

[103] A. Aziz and S. Wheatcroft, "Insulin resistance in type 2 diabetes and obesity: implications for endothelial function," Expert Review of Cardiovascular Therapy, vol. 9, no. 4, pp. 403-407, 2011. 
[104] A. Hatano, Y. Kanno, Y. Kondo et al., "Synthesis and characterization of novel, conjugated, fluorescent DNJ derivatives for $\alpha$-glucosidase recognition," Bioorganic \& Medicinal Chemistry, vol. 25, no. 2, pp. 773-778, 2017.

[105] Q. Liu, X. Li, C. Li et al., "1-Deoxynojirimycin alleviates liver injury and improves hepatic glucose metabolism in $\mathrm{db} / \mathrm{db}$ mice," Molecules, vol. 21, no. 3, p. 279, 2016.

[106] H. Guo, Y. Xu, W. Huang et al., "Kuwanon G preserves LPSinduced disruption of gut epithelial barrier in vitro," Molecules, vol. 21, no. 11, 2016.

[107] H. N. Na, S. Park, H. J. Jeon, H. B. Kim, and J. H. Nam, "Reduction of adenovirus 36-induced obesity and inflammation by mulberry extract," Microbiology and Immunology, vol. 58, no. 5, pp. 303-306, 2014.

[108] H. H. Lim, S. O. Lee, S. Y. Kim, S. J. Yang, and Y. Lim, “Antiinflammatory and antiobesity effects of mulberry leaf and fruit extract on high fat diet-induced obesity," Experimental Biology and Medicine (Maywood, N.J.), vol. 238, no. 10, pp. 1160-1169, 2013.

[109] C. Song, Y. Ji, G. Zou, and C. Wan, "Tetrandrine downregulates expression of miRNA-155 to inhibit signalinduced NF- $\kappa$ B activation in a rat model of diabetes mellitus," International Journal of Clinical and Experimental Medicine, vol. 8, no. 3, pp. 4024-4030, 2015.

[110] E. Zhang, B. Gao, and L. Yang, "Notoginsenoside Ft1 promotes fibroblast proliferation via PI3K/Akt/mTOR signaling pathway and benefits wound healing in genetically diabetic mice," The Journal of Pharmacology and Experimental Therapeutics, vol. 356, no. 2, pp. 324-332, 2016.

[111] M. Du, X. Hu, L. Kou, B. Zhang, and C. Zhang, "Lycium barbarum polysaccharide mediated the antidiabetic and antinephritic effects in diet-streptozotocin-induced diabetic Sprague Dawley rats via regulation of NF- $\kappa \mathrm{B}$," BioMed Research International, vol. 2016, Article ID 3140290, 9 pages, 2016.

[112] A. Hosseini and H. Hosseinzadeh, "A review on the effects of Allium sativum (garlic) in metabolic syndrome," Journal of Endocrinological Investigation, vol. 38, no. 11, pp. 1147$1157,2015$.

[113] R. Zhu, J. Zheng, L. Chen, B. Gu, and S. Huang, "Astragaloside IV facilitates glucose transport in $\mathrm{C} 2 \mathrm{C} 12$ myotubes through the IRS1/AKT pathway and suppresses the palmitate-induced activation of the IKK/I $\kappa \mathrm{B} \alpha$ pathway," International Journal of Molecular Medicine, vol. 37, no. 6, pp. 1697-1705, 2016.

[114] D. Gui, J. Huang, Y. Guo et al., “Astragaloside IV ameliorates renal injury in streptozotocin-induced diabetic rats through inhibiting NF- $\kappa \mathrm{B}$-mediated inflammatory genes expression," Cytokine, vol. 61, no. 3, pp. 970-979, 2013.

[115] L. Du, M. Hao, C. Li et al., "Quercetin inhibited epithelial mesenchymal transition in diabetic rats, high-glucosecultured lens, and SRA01/04 cells through transforming growth factor- $\beta 2$ /phosphoinositide 3-kinase/Akt pathway," Molecular and Cellular Endocrinology, vol. 452, pp. 44-56, 2017.

[116] Y. Qiao, K. Gao, Y. Wang, X. Wang, and B. Cui, "Resveratrol ameliorates diabetic nephropathy in rats through negative regulation of the p38 MAPK/TGF- $\beta 1$ pathway," Experimental and Therapeutic Medicine, vol. 13, no. 6, pp. 3223-3230, 2017.

[117] Y. Jin, X. Guo, B. Yuan et al., "Disposition of astragaloside IV via enterohepatic circulation is affected by the activity of the intestinal microbiome," Journal of Agricultural and Food Chemistry, vol. 63, no. 26, pp. 6084-6093, 2015.

[118] J. Firrman, L. Liu, L. Zhang et al., "The effect of quercetin on genetic expression of the commensal gut microbes Bifidobacterium catenulatum, Enterococcus caccae and Ruminococcus gauvreauii," Anaerobe, vol. 42, pp. 130-141, 2016.

[119] M. M. Sung, T. T. Kim, E. Denou et al., "Improved glucose homeostasis in obese mice treated with resveratrol is associated with alterations in the gut microbiome," Diabetes, vol. 66, no. 2, pp. 418-425, 2017.

[120] X. P. Zhang, J. Jiang, Q. H. Cheng et al., "Protective effects of Ligustrazine, Kakonein and Panax Notoginsenoside on the small intestine and immune organs of rats with severe acute pancreatitis," Hepatobiliary \& Pancreatic Diseases International, vol. 10, no. 6, pp. 632-637, 2011.

[121] L. Zhao, H. Wu, A. Zhao et al., "The in vivo and in vitro study of polysaccharides from a two-herb formula on ulcerative colitis and potential mechanism of action," Journal of Ethnopharmacology, vol. 153, no. 1, pp. 151-159, 2014.

[122] A. Lang, M. Lahav, E. Sakhnini et al., "Allicin inhibits spontaneous and TNF-alpha induced secretion of proinflammatory cytokines and chemokines from intestinal epithelial cells," Clinical Nutrition, vol. 23, no. 5, pp. 1199-1208, 2004.

[123] H. S. Choi, H. S. Kim, K. R. Min et al., "Anti-inflammatory effects of fangchinoline and tetrandrine," Journal of Ethnopharmacology, vol. 69, no. 2, pp. 173-179, 2000.

[124] Y. C. Oh, W. K. Cho, G. Y. Im et al., "Anti-inflammatory effect of Lycium fruit water extract in lipopolysaccharidestimulated RAW 264.7 macrophage cells," International Immunopharmacology, vol. 13, no. 2, pp. 181-189, 2012.

[125] L. F. Cardozo, L. M. Pedruzzi, P. Stenvinkel et al., "Nutritional strategies to modulate inflammation and oxidative stress pathways via activation of the master antioxidant switch Nrf2," Biochimie, vol. 95, no. 8, pp. 1525-1533, 2013.

[126] X. Zhou, X. Sun, X. Gong et al., “Astragaloside IV from Astragalus membranaceus ameliorates renal interstitial fibrosis by inhibiting inflammation via TLR4/NF- $\kappa \mathrm{B}$ in vivo and in vitro," International Immunopharmacology, vol. 42, pp. 18-24, 2017.

[127] Z. Cai, J. Liu, H. Bian, and J. Cai, “Astragaloside IV ameliorates necrotizing enterocolitis by attenuating oxidative stress and suppressing inflammation via the vitamin D3upregulated protein $1 / \mathrm{NF}-\kappa \mathrm{B}$ signaling pathway," Experimental and Therapeutic Medicine, vol. 12, no. 4, pp. 27022708, 2016.

[128] H. Iskender, E. Dokumacioglu, T. M. Sen, I. Ince, Y. Kanbay, and S. Saral, "The effect of hesperidin and quercetin on oxidative stress, NF- $\kappa$ B and SIRT1 levels in a STZ-induced experimental diabetes model," Biomedicine \& Pharmacotherapy, vol. 90, pp. 500-508, 2017.

[129] K. A. Kang, S. Chae, Y. S. Koh et al., "Protective effect of puerariae radix on oxidative stress induced by hydrogen peroxide and streptozotocin," Biological and Pharmaceutical Bulletin, vol. 28, pp. 1154-1160, 2005.

[130] R. Li, Y. Chen, M. Shi et al., "Gegen Qinlian decoction alleviates experimental colitis via suppressing TLR4/NF- $\kappa \mathrm{B}$ signaling and enhancing antioxidant effect," Phytomedicine, vol. 23, no. 10, pp. 1012-1020, 2016.

[131] C. H. Zhang, G. L. Xu, Y. H. Liu et al., "Anti-diabetic activities of Gegen Qinlian decoction in high-fat diet combined with 
streptozotocin-induced diabetic rats and in 3T3-L1 adipocytes," Phytomedicine, vol. 20, no. 3-4, pp. 221-229, 2013.

[132] Y. M. Li, X. M. Fan, Y. M. Wang, Q. L. Liang, and G. A. Luo, "Therapeutic effects of Gegen Qinlian decoction and its mechanism of action on type 2 diabetic rats," Acta Pharmaceutica Sinica, vol. 48, no. 9, p. 1415, 2013.

[133] V. Tremaroli and F. Backhed, "Functional interactions between the gut microbiota and host metabolism," Nature, vol. 489, pp. 242-249, 2012.

[134] P. J. Turnbaugh, R. E. Ley, M. A. Mahowald, V. Magrini, E. R. Mardis, and J. I. Gordon, "An obesity-associated gut microbiome with increased capacity for energy harvest," Nature, vol. 444, pp. 1027-1031, 2006.

[135] J. Xu, F. Lian, L. Zhao et al., "Structural modulation of gut microbiota during alleviation of type 2 diabetes with a Chinese herbal formula," ISME Journal, vol. 9, no. 3, p. 552, 2015.

[136] L. Zheng and Y. H. Quan, "Experience of treating side effects of antibiotic abuses by professor Quan Yihong's Dangguiliuhuang decoction," Journal of Hubei University of Chinese Medicine, vol. 16, pp. 107-109, 2014.

[137] T. Liu, H. Cao, Y. Ji et al., "Interaction of dendritic cells and $\mathrm{T}$ lymphocytes for the therapeutic effect of Dangguiliuhuang decoction to autoimmune diabetes," Scientific Reports, vol. 5, 2015.

[138] S. B. Kim, O. H. Kang, J. H. Keum et al., “Anti-inflammatory effects of Danggui Liuhuang decoction in RAW 264.7 cells," Chinese Journal of Integrative Medicine, 2012.

[139] G. Baorong and G. Liangqing, "Clinical observation of Huanglian Wendan Heji (Huanglian Wendan mixture) in treatment of damp-heat type of gerontic diabetes gastroparesis," World Journal of Traditional Chinese Medicine, vol. 2, p. 008, 2007.

[140] L. Liu and Y. Sui, "The effect of Huanglianwendan decoction on insulin resistance and adipocytokines in metabolic syndrome rats," Liaoning Journal of Traditional Chinese Medicine, vol. 3, p. 002, 2011.

[141] Y. B. Li, W. H. Zhang, H. D. Liu, Z. Liu, and S. P. Ma, "Protective effects of Huanglian Wendan decoction aganist cognitive deficits and neuronal damages in rats with diabetic encephalopathy by inhibiting the release of inflammatory cytokines and repairing insulin signaling pathway in hippocampus," Chinese Journal of Natural Medicines, vol. 14, no. 11 , pp. 813-822, 2016. 


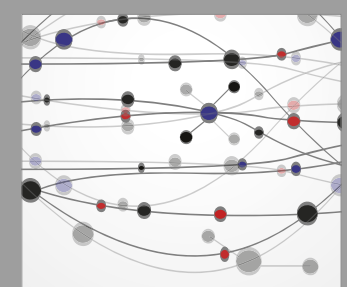

The Scientific World Journal
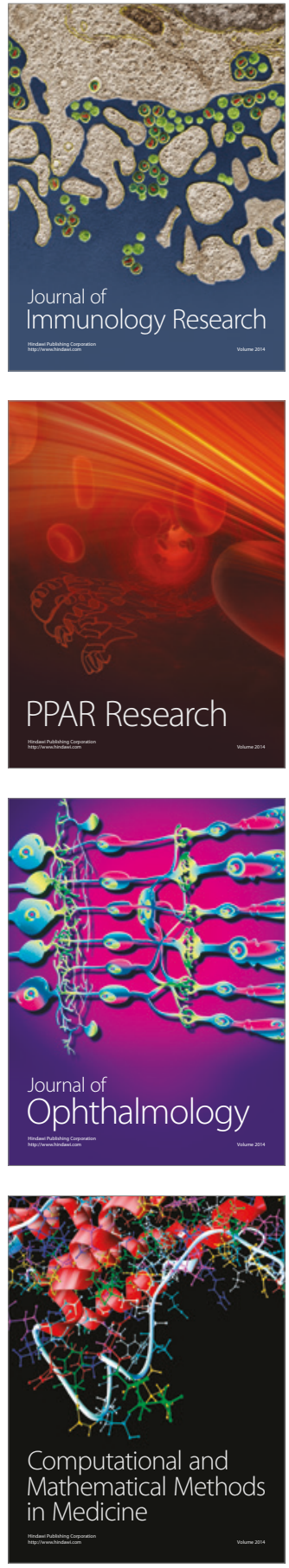

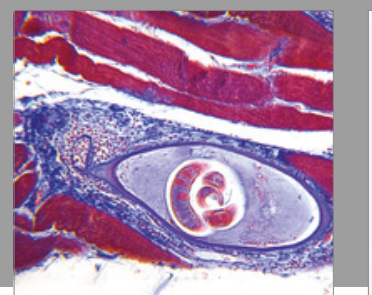

Gastroenterology Research and Practice
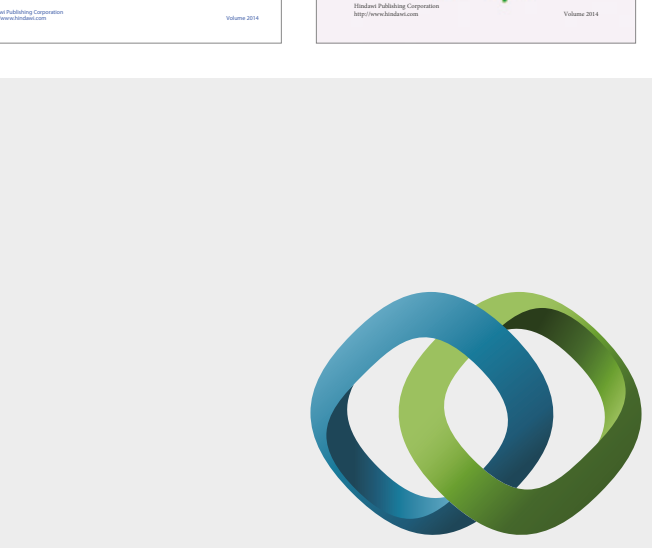

\section{Hindawi}

Submit your manuscripts at

https://www.hindawi.com
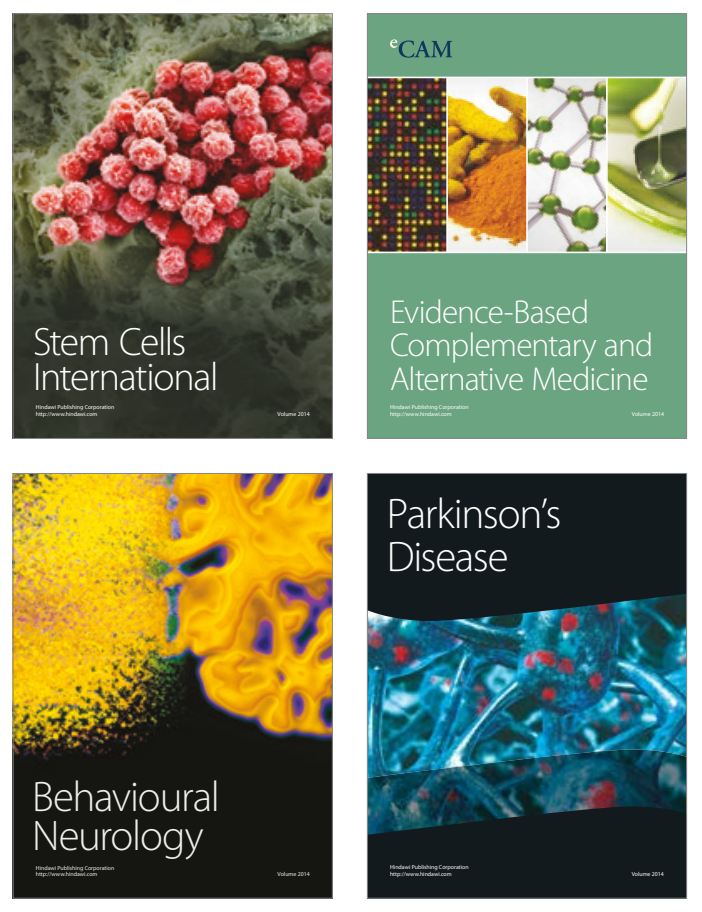
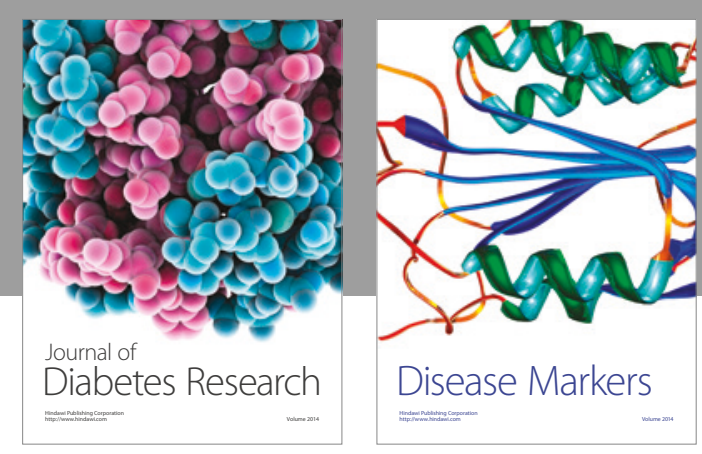

Disease Markers
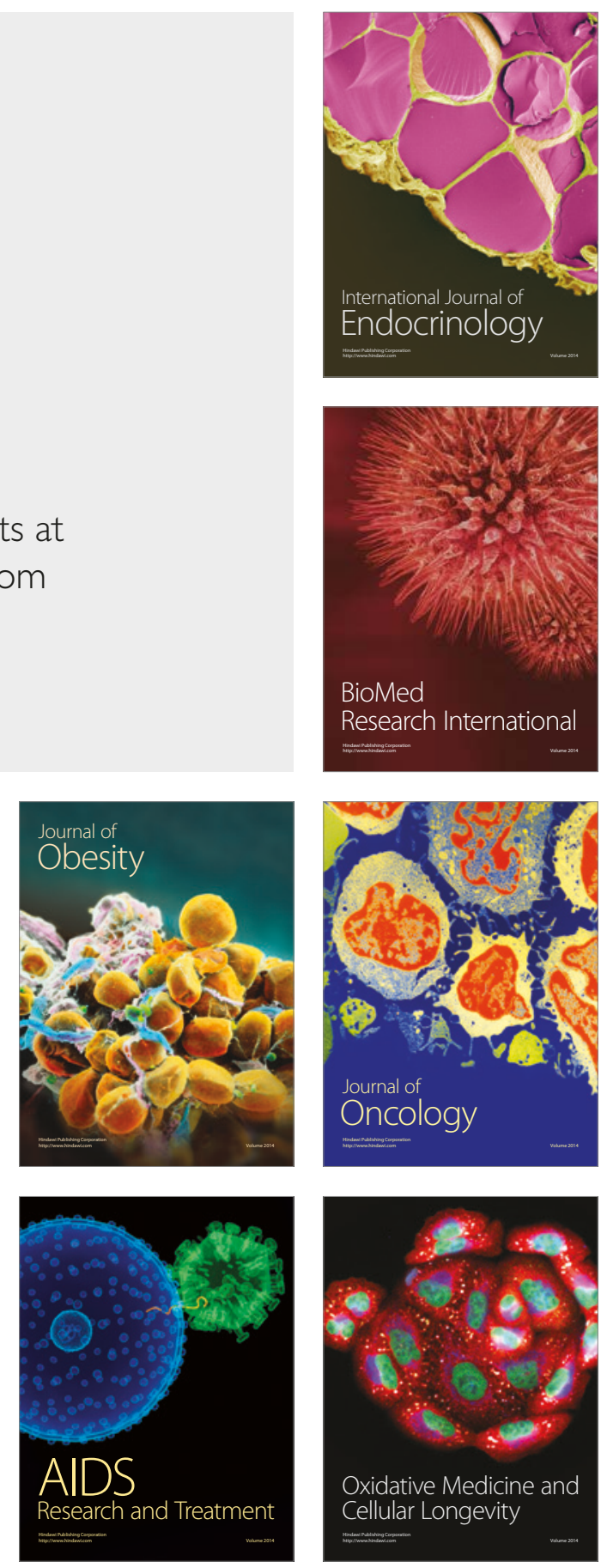